\title{
Predicting the risk of arsenic contaminated groundwater in Shanxi Province, Northern China
}

\author{
Qiang Zhang ${ }^{\mathrm{a}}$, Luis Rodríguez-Lado ${ }^{\mathrm{b}}, \mathrm{C}$. Annette Johnson ${ }^{\mathrm{b}}$, Hanbin Xue ${ }^{\mathrm{b}}$, Jianbo Shi ${ }^{\mathrm{c}}$, \\ Quanmei Zheng a, Guifan Sun ${ }^{\mathrm{a}, *}$ \\ a Department of Occupational and Environmental Health, College of Public Health, China Medical University, No. 92 Bei Er Road, Heping District, 110001 Shenyang, China \\ ${ }^{\mathrm{b}}$ Eawag, Swiss Federal Institute of Aquatic Science and Technology, 8600 Dubendorf, Switzerland \\ ' State Key Laboratory of Environmental Chemistry and Ecotoxicology, Research Center for Eco-Environmental Sciences, Chinese Academy of Sciences, 100085 Beijing, China
}

\section{A R T I C L E I N F O}

\section{Article history:}

Received 9 July 2011

Received in revised form

20 February 2012

Accepted 21 February 2012

\section{Keywords:}

Geogenic pollution

Arsenicosis

Logistic regression

Spatial modeling

\begin{abstract}
A B S T R A C T
Shanxi Province is one of the regions in northern China where endemic arsenicosis occurs. In this study, stepwise logistic regression was applied to analyze the statistical relationships of a dataset of arsenic (As) concentrations in groundwaters with some environmental explanatory parameters. Finally, a 2D spatial model showing the potential As-affected areas in this province was created. We identified topography, gravity, hydrologic parameters and remote sensing information as explanatory variables with high potential to predict high As risk areas. The model identifies correctly the already known endemic areas of arsenism. We estimate that the area at risk exceeding $10 \mu \mathrm{g} \mathrm{L}^{-1}$ As occupies approximately $8100 \mathrm{~km}^{2}$ in 30 counties in the province.
\end{abstract}

(c) 2012 Published by Elsevier Ltd.

\section{Introduction}

Arsenic (As), a well documented toxic metalloid, is a group I carcinogen, which typically causes skin, lung and bladder cancer (WHO, 2001). Exposure to As via drinking water can be the cause of severe health hazards to humans, including various skin lesions (Tondel et al., 1999), hypertension (Chen et al., 1995), cardiovascular diseases (States et al., 2009), diabetes (Navas-Acien et al., 2008; Tseng et al., 2000), as well as black foot disease (Tseng, 1977). It has been estimated that over 100 million people worldwide are consuming As-contaminated groundwater (Carbonell-Barrachina et al., 2009), constituting an important threat to human health.

China is one of the most severely affected countries in the world and it is estimated that more than 3 million people are exposed to high levels of As (Sun, 2004). Since the first cases of chronic As poisoning were observed in the Xinjiang autonomous region in 1980 (Wang and Huang, 1994), new endemic areas, such as the Hetao and Huhot basins in Inner Mongolia (Guo et al., 2001) or the Datong Basin in Shanxi Province (Wang et al., 2007), have been progressively identified. The Chinese government has published policies to prevent and control the endemic arsenicosis and a large

\footnotetext{
* Corresponding author.

E-mail address: sungf@mail.cmu.edu.cn (G. Sun).
}

budget has been allocated for the identification of As-contaminated areas and affected population (Luong et al., 2004). To increase the efficiency of the field survey, Sun (2004) developed a "10\% sampling method", which is being widely used in the national investigation. The Chinese Ministry of Health carried out sampling campaigns between 2001 and 2005, in which 445,638 wells in 20,517 villages of 292 counties (roughly $12 \%$ of counties in China) were tested for elevated As concentrations. Almost $5 \%$ of wells were found to have As levels higher than the Chinese standard threshold of $50 \mu \mathrm{g} \mathrm{L}^{-1}$ (Yu et al., 2007). A spatial model predicting the regions prone to high As concentrations would accelerate the screening by prioritizing the sampling at those areas with higher potential risk.

Statistical models based on the statistical relationship of As concentrations and relevant explanatory variables such as geology, climate or topography have recently been developed (Amini et al., 2008; Rodríguez-Lado et al., 2008; Winkel et al., 2008). Logistic regression has been successfully used to assess the probability that As concentrations exceed a pre-defined threshold (Lee et al., 2009; Twarakavi and Kaluarachchi, 2006; Winkel et al., 2011).

Shanxi, Xinjiang and Inner Mongolia are the main provinces in northern China, where most of the arsenicosis patients have been identified. Shanxi has the highest population density among these three provinces. Topography is mainly mountainous and, due to the dominant semi-arid climate, most of the population is located along the 6 basins shown in Fig. 1. The first endemic arsenism 


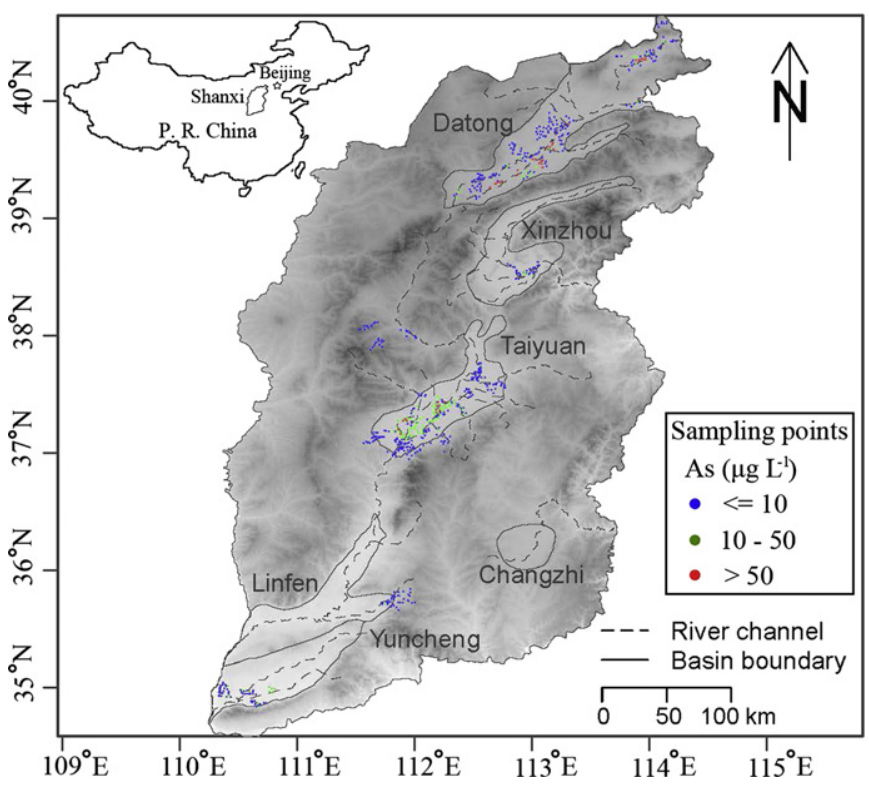

Fig. 1. Distribution of the sampling points and location of the main rivers and basins in Shanxi Province. The map of elevations is shown as background.

cases were reported in 1994 in the Shanyin County (Datong Basin), where As concentrations as high as $4350 \mu \mathrm{g} \mathrm{L}^{-1}$ were found (Cheng et al., 1994). Wang et al. (2007) reported that the Datong $\left(1350 \mathrm{~km}^{2}\right)$ and Taiyuan $\left(800 \mathrm{~km}^{2}\right)$ basins are the two main endemic areas in Shanxi Province, with 3998 individuals diagnosed with arsenicosis and elevated As concentrations found in several counties (Wang et al., 2004, 2007, 2008). In addition, Li et al. (2007) reported As levels in 288 water samples ranging from 0.2 to $720 \mu \mathrm{g} \mathrm{L}^{-1}$ in the Datong Basin, and Guo and Zhang (2007) found As concentrations ranging between $0.1-116 \mu \mathrm{g} \mathrm{L}^{-1}$ in 44 samples from the Taiyuan Basin.

It is generally agreed that there are two main processes controlling the mobilization of As to the groundwaters: (1) Microbially mediated reductive dissolution of Fe oxi-hydroxides is the main process leading to the release of As under reducing conditions in young alluvial and deltaic sediments containing elevated organic carbon contents (Amini et al., 2008; Islam et al., 2004; Roberts et al., 2010). (2) Alkali desorption of arsenate from iron-oxide surfaces occurring in oxidizing environments in arid and semi-arid climates with high pH (Nicolli et al., 2010; Nordstrom, 2002; Smedley and Kinniburgh, 2002).

To date almost all As research performed in Shanxi Province has focused on the Datong and Taiyuan Basins. It is not known whether As contaminates the groundwater in the other densely populated basins. Quaternary aquifers are the most important source of groundwater in these basins (Guo et al., 2007a; Wang et al., 2009; Xie et al., 2009) and, despite waters rich in $\mathrm{NaHCO}_{3}$ predominate (Currell et al., 2011; Xie et al., 2008), it appears that high As concentrations are exclusively correlated to reducing conditions in the basins (Guo et al., 2003; Li et al., 2007; Xie et al., 2009).

Due to limited funds, the local government focuses on known endemic villages. Villages far away from the endemic areas may also be at risk but they have not yet been identified. In this study, we developed a statistical model, based in stepwise logistic regression, to predict the location of As-affected areas of Shanxi Province. We used field As measurements as response and a number of environmental parameters as predictor variables and the threshold guideline of the World Health Organization $\left(10 \mu \mathrm{g} \mathrm{L}^{-1}\right)$ as guideline value. The results of the model have been finally validated upon already published As data.

\section{Materials and methods}

\subsection{Study area}

Shanxi Province is situated to the east of the Yellow River valley of northern China (Fig. 1) and covers an area of $156,000 \mathrm{~km}^{2}$. It has an estimated population of 34 million people distributed in 119 counties. The climate is temperate with a mild continental monsoon and four distinct seasons. The annual average temperatures range from -4 to $14{ }^{\circ} \mathrm{C}$ and the annual average precipitation is around 400-650 mm. It presents an intricate topography which includes mountains, hills, plateaus and basins. Most of the area is formed by mountainous areas and loess plateaus but basin areas are also important including the Datong Basin, Xinzhou Basin, Taiyuan Basin, Linfen Basin, Changzhi Basin, and Yuncheng Basin (Fig. 1). In general, water is a scarce resource in the whole province.

\subsection{Arsenic dataset}

The As database has been obtained from the Center for Disease Control and Prevention of Shanxi Province, developed under the Central Finance Transfer Payment Project, founded by the Chinese Government. The data was collected using the " $10 \%$ sampling method" previously cited. The dataset consists of As concentration measurements from 5081 sampled wells in 712 villages. The dataset is aggregated at village level and contains information about the total number of sampled wells, the number of wells with As concentrations above and below the threshold values of 10 and $50 \mu \mathrm{g} \mathrm{L}^{-1}$ and the maximum and minimum As content found at each village. The samples have been geospatially located and the As concentrations transformed to a binary-code following to the As thresholds. A second database, containing 87 As concentrations in wells from the Datong Basin and Yuncheng Basin, has been created from published data (Currell et al., 2011; Xie et al., 2009). We excluded two spring samples in the Datong Basin and one sample in the Yuncheng Basin with an abnormally high As concentration, probably affected by local contamination. This database has been used to validate the model results.

\subsection{Explanatory variables}

A number of 23 surface and subsurface parameters, considered to be closely related to the release of As in groundwaters, have been used as explanatory variables within a logistic regression model to predict the As hazard risk at un-sampled locations of Shanxi Province. These variables, in the form of raster maps at $1 \mathrm{~km}$ resolution have been sorted into six categories.

\subsubsection{Topographic variables}

A Digital Elevation Model (DEM) at $500 \mathrm{~m}$ resolution was obtained from the Consortium for Spatial Information and up-scaled to $1 \mathrm{~km}$ resolution (Jarvis et al., 2008). We used SAGA-GIS (SAGA Development Team, 2008) to calculate the following DEM derived parameters: (1) Topographic Wetness Index (TWI), (2) Catchment slope, (3) Topographic index, (4) Modified Catchment Area (MCA), (5) Slope and (6) Elevation. These variables can correlate with hydrologic processes of the aquifer (Ayotte et al., 2006). Studies in Cambodia and Bangladesh revealed that there is a strong correlation between topographic environmental variables and the content of As in groundwater (Rodríguez-Lado et al., 2008; Shamsudduha et al., 2009).

\subsubsection{Remote sensing information}

Remote sensing information are used for mapping and monitoring land-cover and land-use change (Rogan and Chen, 2004; Shalaby and Tateishi, 2006). This variable shows the effect of climate on distribution of vegetation which abundant in the tropical areas and lack in arid regions. In arid regions, it clearly discriminates the areas used for agriculture, mainly in areas along large rivers and where human settlement are mostly located and where most of the As contaminated wells have been found. In this study, we used eight images of "Enhanced Vegetation Index" (EVI) from the "Moderate Resolution Imaging Spectroradiometer" (MODIS) at $250 \mathrm{~m}$ resolution and time-lag of 4 months. These images cover a temporal series of two consecutive years. The images have been up-scaled to $1 \mathrm{~km}$ resolution and synthesized by "Principal Component Analysis" (PCA) to avoid redundancy in the information within the time series. The eight raster maps derived from the PCA (EVI1 to EVI8) have been used as explanatory variables.

\subsubsection{Geology}

Holocene sediments are closely related to high arsenic in groundwater (Smedley and Kinniburgh, 2002; Mukherjee et al., 2009). A binary map at $1 \mathrm{~km}$ resolution showing the Holocene sedimentary areas has been created from the information in the Geologic Map of Shanxi at 1:500,000 scale.

\subsubsection{Soil information}

We evaluated information on soil characteristics including $\mathrm{pH}$, salinity, texture, and so on, since soil features are factors of high As in groundwaters in south and east Asia (Smedley, 2003; Xie et al., 2008). Soil properties were complied from the "Harmonized World Soil Database" (FAO/IIASA/ISRIC/ISSCAS/JRC, 2009). This 
database contains information of both topsoil and subsoil properties at 1:1,000,000 scale based on the Second National Soil Survey of China. We selected those properties that could have a potential influence on the release of As to the groundwaters. The following soil properties have been included in our model calibration: Soil pH, soil salinity, soil texture, soil electrical conductivity (soil ECE), and soils associated to alluvial, lacustrine and saline environments (soil type). These parameters have been reclassified to binary maps at $1 \mathrm{~km}$ resolution based on the following rules: (1) soil pH higher or lower than 7.0; (2) soils showing Inundic and Salic properties; (3) soils with Clay Loam, Sandy Clay and Loam texture; (4) soil ECE greater or less than $1 \mathrm{dS} / \mathrm{m}$; (5) soils associated to alluvial, lacustrine and saline environments. This last parameter has been made to identify, within the generic class of Quaternary sediments, the areas with higher potential for As mobilization.

\subsubsection{Hydrology}

The river network data of China at 1:1,000,000 scale was used to calculate raster maps of density of rivers (Rivdens) and distance to rivers (Rivdist) at $1 \mathrm{~km}$ resolution. These two features may influence hydrologic processes that affect As levels in groundwater.

\subsubsection{Gravity}

The gravitational force is not uniformly distributed everywhere on the Earth, which results from its irregular shape, density variations of sediment and thickness of solid and rocky crust. However, the depth of the sediments is a piece of missing information in the geologic maps available for Shanxi Province. Gravity data provides information about the density of earth materials below the earth surface. We could use gravity maps to improve the information provided by the geologic maps. In this study, we used the gravity map at $1 \mathrm{~km}$ resolution, provided by Dr. Ole Baltazar at the Technical University of Denmark, to improve the identification of the sedimentary areas within the province.

\subsection{Statistical analysis}

All the statistical analyses have been carried out using the statistical environment "R" (R Development Core Team, 2008). A Principal Component Analysis of the data has been performed to summarize the data in fewer dimensions to identify the main process governing the release of As within the dataset.

Logistic regression with stepwise selection of the significant variables has been used to analyze the relationships between a binary response variable (high/low As concentrations) and the set of explanatory variables to create a predictive model of the probability for high/low As hazard risk using a certain As threshold value. The model takes the following form:

$$
\begin{aligned}
P[y=1 \mid x]= & {\left[\operatorname{Exp}\left(\beta_{0}+\beta_{1} X_{1}+\beta_{2} X_{2}+\cdots+\beta_{n} X_{n}\right)\right] /\left[1+\operatorname{Exp}\left(\beta_{0}+\beta_{1} X_{1}+\beta_{2} X_{2}+\cdots\right.\right.} \\
& \left.\left.+\beta_{n} X_{n}\right)\right]
\end{aligned}
$$

where $P$ is probability of occurring an event, $y$ is the response variable, $\beta_{0}$ is the intercept of regression, $\beta_{1}, \beta_{2}, \ldots$, and $\beta_{n}$ are the weighting coefficients of the explanatory variables, $X_{1}, X_{2}, \ldots$, and $X_{n}$.

In this study the sampling points were divided randomly into two subsets. The first subset, including $80 \%$ of the samples $(n=569)$ was used to construct the logistic regression model; the remaining subset, $20 \%$ of the samples $(n=143)$ was used for the validation of the model. We calculated the Receiver Operating Characteristics (ROC) curve upon the validation dataset to determine the optimal cutoff probability threshold that was finally used to classify our probability map into a binary map representing areas at risk for As hazard.

\section{Results and discussion}

\subsection{Arsenic database}

The total database of As concentrations (Fig. 1) is composed of 712 sampling points mostly located in the basin areas for Datong Basin $(n=226)$, Xinzhou Basin $(n=31)$, Taiyuan Basin $(n=320)$, Linfen Basin $(n=37)$, and Yuncheng Basin $(n=65)$. The contents of As vary from $<10$ to $500 \mu \mathrm{g} \mathrm{L}^{-1}$, with a mean value of $24 \mu \mathrm{g} \mathrm{L}^{-1}$. About $23 \%$ of the sampling points have As levels exceeding the WHO guideline value of $10 \mu \mathrm{g} \mathrm{L}^{-1}$ and 6\% exceeding the Chinese guideline value of $50 \mu \mathrm{g} \mathrm{L}^{-1}$. The higher As values are located in the Datong and Taiyuan Basins.

The sampling points with elevated As are predominantly located in the center of the basins and distributed near by the river channels (Fig. 1). Drainage area of Sanggan River, Huangshui River and Nanyang River in Datong Basin and Fen River in Taiyuan Basin are the most severely affected areas. This indicates that topographic and hydrological features may be associated with groundwater As levels. Other endemic arsenism areas in China also have the same terrain characteristics. Wang and Huang (1994) reported high As concentrations were found in deep artesian groundwater in Dzungaria Basin in Xinjiang Autonomous Region. High As was also found in Huhhot Basin and Hetao plain (Inner Mongolia) and the lowest-lying part of the basins are the worst affected areas (Deng et al., 2008; Smedley et al., 2001).

\subsection{Principal component analysis}

The plot of the loadings of the variables (Fig. 2) on the two main components shows that there is a group of variables (Topographic Wetness Index, presence of alluvial and lacustrine soils in Holocene sediments, soil texture and salinity, Topographic Index, Modified Cathment Area, EVI2, EVI4 and EVI8), that are positively correlated to the First Principal Component (PC1). We interpret this axis as an indicator of environmental reducing conditions. The score values for the samples have been plotted in different colors according to three categories of As ranges. It shows that the higher As concentrations are positively related to the first component. We interpret that, in our study area, the high As concentrations are related to processes of reductive dissolution in reducing environments. Studies in Northern China showed that groundwaters exist in the reducing conditions and high As levels in groundwaters are enhanced by both high salinity and alkalinity in the semiarid-arid areas (Guo et al., 2008; Xie et al., 2008).

\subsection{Logistic regression model}

Logistic stepwise regression has been used to determine the model coefficients and their statistical significance. From the 23 initial variables, only 7 parameters have been retained by the model as significant after the stepwise method. As presented in Table 1, the logistic regression model shows that EVI7, Topographic Wetness Index and the presence of Holocene Sediments are

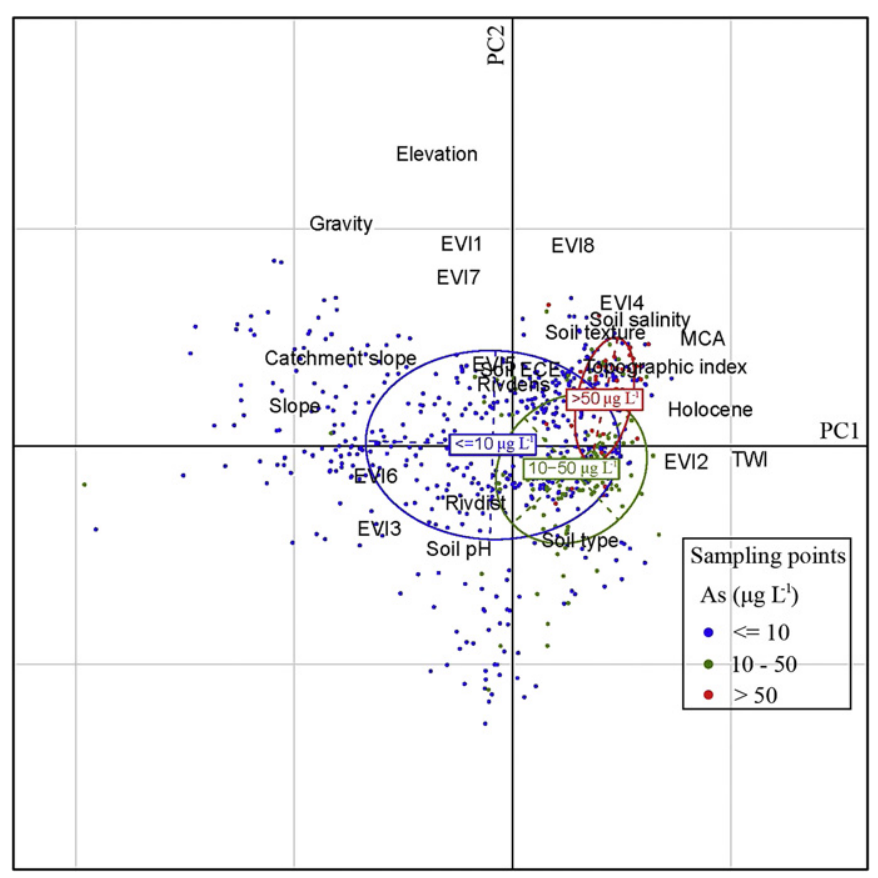

Fig. 2. Principal component analysis. Arsenic concentrations are displayed in different colors for visualization over the plot of the scores. (For interpretation of the references to color in this figure legend, the reader is referred to the web version of this article.) 
Table 1

Significant variables of logistic regression model based on $10 \mu \mathrm{g} \mathrm{L}^{-1}$.

\begin{tabular}{llrlrl}
\hline Category & Variable $^{\mathrm{a}}$ & Estimate & Std. error & $t$ Value & $p$ Value $^{\mathrm{b}}$ \\
\hline Remote & EVI1 & -3.9807 & 1.8340 & -2.171 & $0.02997^{*}$ \\
$\begin{array}{c}\text { sensing } \\
\text { image }\end{array}$ & EVI6 & -3.2101 & 1.6352 & -1.963 & $0.04964^{*}$ \\
EVI7 & 11.0569 & 4.4028 & 2.511 & $0.01203^{*}$ \\
Topography & Topographic & 8.2218 & 2.7153 & 3.028 & $0.00246^{* *}$ \\
& wetness index & & & & \\
Gravity & Gravity & -7.2721 & 2.2742 & -3.198 & $0.00139^{* *}$ \\
Hydrology & Distance & -4.6250 & 1.8067 & -2.560 & $0.01047^{*}$ \\
& to rivers & & & & \\
Geology & Holocene & 0.8094 & 0.3958 & 2.045 & $0.04085^{*}$ \\
& Intercept & -10.3914 & 3.5794 & -2.903 & $0.00369^{* *}$ \\
\hline
\end{tabular}

a EVI, Enhanced vegetation index.

b Significance: “**” $P<0.01$, “*” $P<0.05$.

positively associated with high As levels while EVI1, EVI6, Gravity, and Distance to rivers are negatively associated.

The presence of Holocene sediments as a significant predictor of high As areas in reducing environments agrees with the findings from recent predictive models in Cambodia and Southeast Asia (Rodríguez-Lado et al., 2008; Winkel et al., 2008). Our results indicate that TWI plays an important role in the model calibration. This topographic index, combines local upslope contributing area and slope and seems to be a key to understand much of the hydrological processes and soil properties (Sørensen et al., 2006; Yimer et al., 2006). It is reported that TWI was positively correlated with soil organic matter (Pei et al., 2010), which indirectly supports the central role of organic matter in the mobilization of As in groundwater (Berg et al., 2008; Fendorf et al., 2010; Rowland et al., 2007). As expected from Fig. 1, Distance to rivers is negatively associated with elevated As levels. This indicates that villages in the center of the basin are more prone to have higher concentrations of As in groundwaters. Xie et al. (2009) showed that As concentrations are very high in the central deeper parts of Datong Basin (68-670 $\left.\mu \mathrm{g} \mathrm{L}^{-1}\right)$. Study in Cambodia also indicated that high As groundwaters were observed near the Mekong River (Polizzotto et al., 2008). However, Guo et al. (2011) reported that drainage and irrigation channels in the Hetao Plain (Inner Mongolia) creates suboxic-weakly reducing conditions that produces oxigen-rich waters, recharges the shallow aquifer and immobilize As. Our model also shows that gravity makes a large contribution to the model calibration. Even if the role of gravity in the mobilization of As in groundwater is unclear, it seems that, in our study, low gravity values are associated to the presence of low mass sediments, where most of the elevated As concentrations occur. In addition, we found that some remote sensing information (EVI1, EVI6, and EVI7), related to climate and to the presence of vegetation and thus to water availability can be used to predict variations in As concentrations in groundwaters.

\subsection{Arsenic probability map and binary map}

As a result of the logistic regression model on As risk of Shanxi Province, Fig. 3A showing the probability of groundwater As concentrations exceeding $10 \mu \mathrm{g} \mathrm{L}^{-1}$ has been created. The highest probabilities ( $>0.8$ ) were found at the junction of Hongtong County and Linfen City within Linfen Basin. A cutoff probability value of 0.22 has been calculated on the validation dataset using the ROC curve. This value served to classify the previously created probability map into a binary map of high and low risk (Fig. 3B). This map shows that area at risk for As concentration above $10 \mu \mathrm{g} \mathrm{L}^{-1}$ accounts for $8112 \mathrm{~km}^{2}$, in more than 30 counties. Most of the predicted areas at risk are distributed in the basin areas. High risk predicted areas, such as the Datong Basin, Taiyuan Basin, and part of the Yuncheng Basin, agree well with the known high As contaminated areas (Currell et al., 2011; Guo et al., 2007b; Yu et al., 2007). However, the information from large areas predicted at high risk by the model such as the Xinzhou Basin and Linfen Basin is poor and, for such areas our model results can not be validated. Although the high uncertainty in these maps, they can be used as a primary step for the environmental and health intervention in this province.

\subsection{Model validation}

The overall accuracy calculated upon the validation dataset $(20 \%$ samples) is $68.3 \%$. 64.2\% of the As concentrations exceeding $10 \mu \mathrm{g} \mathrm{L}^{-1}$ (sensitivity) where correctly classified by the model, while this number increases when predicting low arsenic concentrations (specificity $=81.8 \%$ ). The overall accuracy of the model using the dataset from bibliography decreases to $63.2 \%$, with $69.2 \%$ and $60.7 \%$ of sensitivity and specificity respectively. These differences are probably due to the smaller number of samples and their clustered location in the data obtained from bibliography.
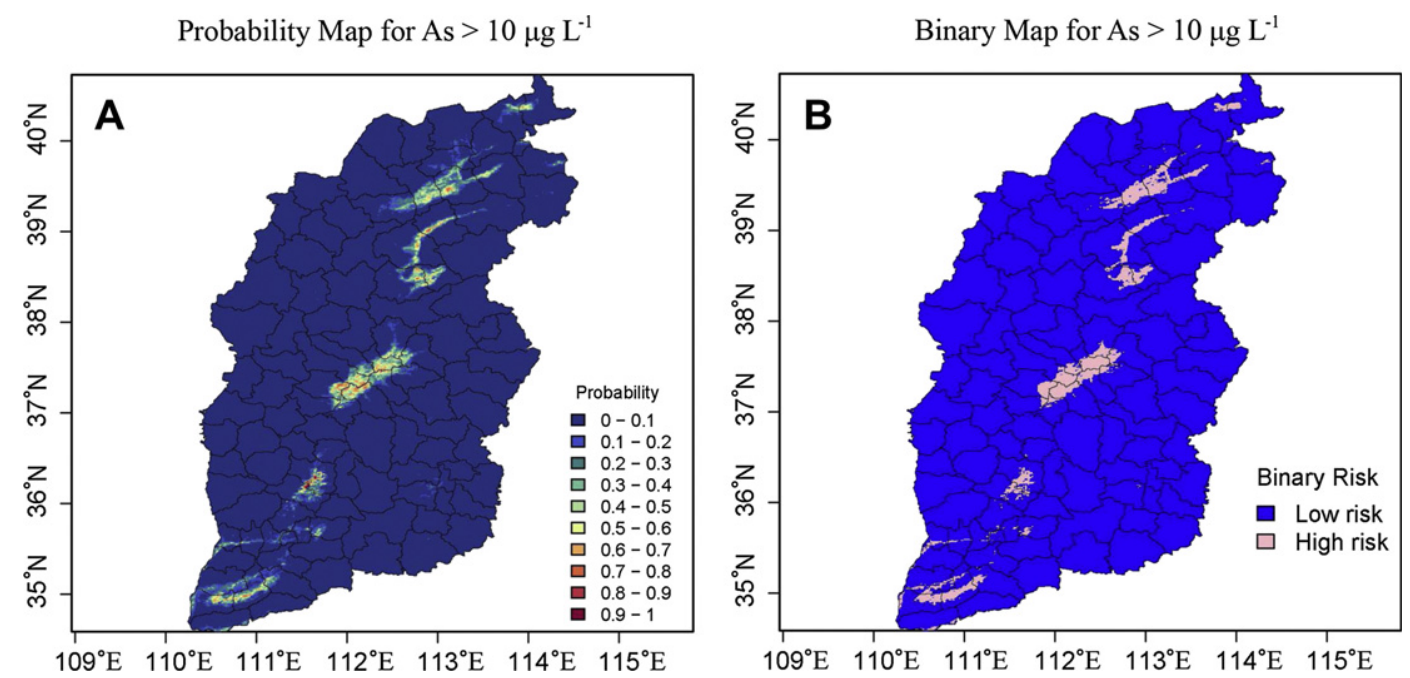

Fig. 3. Model results of arsenic concentration above $10 \mu \mathrm{g} \mathrm{L}{ }^{-1}$. (A) Arsenic probability map; (B) Binary map based on the cutoff probability. 


\section{Conclusions}

The existing information of the areas at risk for As contamination in groundwater of Shanxi Province is scarce and modeling methods provide a means to a quick identification of potentially affected areas, which is not already identified. Our findings support that the main process governing the release of As to the groundwaters is reductive dissolution of Fe oxi-hydroxides under reducing conditions. We identified some environmental parameters that can explain the distribution of high As concentrations: (1) Holocenic sediments; (2) Topographic Wetness Index; (3) hydrological characteristics (Distance to rivers); (4) Gravity; and (5) Remote sensing information. The spatial patterns of the risk map agreed well with the already established high As contaminated areas and highlighted new areas with high potential for As pollution. Although the moderate accuracy values obtained in the validation process, we think that this map could be used as a reference to target the effort of screening rationally.

\section{Acknowledgements}

This study has been developed within the framework of the project "Risk Maps of Arsenic Contamination in Groundwaters of China (REMARC)". The authors would like to thank the Sino-Swiss Science and Technology Cooperation (SSSTC) program, the National Science and Technology Pillar Program of China during the 11th Five-Year Plan Period (No. 2006BAI06B04) and the External Cooperation Program of Chinese Academy of Sciences (GJHZ 0907) for the financial support to this project.

\section{References}

Amini, M., Abbaspour, K.C., Berg, M., Winkel, L., Hug, S.J., Hoehn, E., Yang, H., Johoson, C.A., 2008. Statistical modeling of global geogenic arsenic contamination in groundwater. Environmental Science and Technology 42, 3669-3675.

Ayotte, J.D., Nolan, B.T., Nuckols, J.R., Cantor, K.P., Robinson, G.R., Baris, D., Hayes, L., Karagas, M., Bress, W., Silverman, D.T., Lubin, J.H., 2006. Modeling the probability of arsenic in groundwater in New England as a tool for exposure assessment. Environmental Science and Technology 40, 3578-3585.

Berg, M., Trang, P.T.K., Stengel, C., Buschmann, J., Viet, P.H., Van Dan, N., Giger, W., Stüben, D., 2008. Hydrological and sedimentary controls leading to arsenic contamination of groundwater in the Hanoi area, Vietnam: the impact of ironarsenic ratios, peat, river bank deposits, and excessive groundwater abstraction. Chemical Geology 249, 91-112.

Carbonell-Barrachina, A.A., Signes-Pastor, A.J., Vázquez-Araújo, L., Burló, F., Sengupta, B., 2009. Presence of arsenic in agricultural products from arsenicendemic areas and strategies to reduce arsenic intake in rural villages. Molecular Nutrition \& Food Research 53, 531-541.

Chen, C.J., Hsueh, Y.M., Lai, M.S., Shyu, M.P., Chen, S.Y., Wu, M.M., Kuo, T.L., Tai, T.Y., 1995. Increased prevalence of hypertension and long-term arsenic exposure. Hypertension 25, 53-60.

Cheng, J.S., Mi, E.F., Zhang, Q.X., 1994. Preliminary report of epidemiological investigation of endemic arsenism in Shanxi Province. Shanxi Journal of Preventive Medicine 3,133-135 (in Chinese).

Currell, M., Cartwright, I., Raveggi, M., Han, D., 2011. Controls on elevated fluoride and arsenic concentrations in groundwater from the Yuncheng Basin, China. Applied Geochemistry 26, 540-552.

Deng, Y.M., Wang, Y.X., Ma, T., Gan, Y.Q., 2008. Speciation and enrichment of arsenic in strongly reducing shallow aquifers at western Hetao Plain, northern China. Environmental Geology 56, 1467-1477.

FAO/IIASA/ISRIC/ISSCAS/JRC, 2009. Harmonized World Soil Database (version 1.1). FAO/IIASA, Rome, Italy, Laxenburg and Austria.

Fendorf, S., Michael, H.A., Geen, A.V., 2010. Spatial and temporal variations of groundwater arsenic in South and Southeast Asia. Science 328, 1123-1127.

Guo, H.M., Wang, Y.X., Shpeizer, G.M., Yan, S.L., 2003. Natural occurrence of arsenic in shallow groundwater, Shanyin, Datong Basin, China. Journal of Environmental Science and Health, Part A: Toxic/Hazardous Substances and Environmental Engineering 38, 2565-2580.

Guo, H.M., Yang, S.Z., Tang, X.H., Li, Y., Shen, Z.L., 2008. Groundwater geochemistry and its implications for arsenic mobilization in shallow aquifers of the Hetao Basin, Inner Mongolia. Science of the Total Environment 393, 131-144.

Guo, H.M., Zhang, B., Li, Y., Berner, Z., Tang, X.H., Norra, S., Stüben, D., 2011. Hydrogeological and biogeochemical constrains of arsenic mobilization in shallow aquifers from the Hetao basin, Inner Mongolia. Environmental Pollution $159,876-883$.
Guo, Q.H., Wang, Y.X., Gao, X.B., Ma, R., 2007b. A new model (DRARCH) for assessing groundwater vulnerability to arsenic contamination at basin scale: a case study in Taiyuan basin, northern China. Environmental Geology 52, 923-932.

Guo, Q.H., Wang, Y.X., Ma, T., Ma, R., 2007a. Geochemical processes controlling the elevated fluoride concentrations in groundwaters of the Taiyuan Basin, Northern China. Journal of Geochemical Exploration 93, 1-12.

Guo, Q.H., Zhang, L.H., 2007. Distribution of arsenic and other aqueous constituents in groundwater of Taiyuan basin, China. In: Wang, Y.X., Bullen, T.D. (Eds.), Water-Rock Interaction. Taylor and Francis, London, pp. 1299-1303.

Guo, X.J., Fujino, Y., Kaneko, S., Wu, K.G., Xia, Y.J., Yoshimura, T., 2001. Arsenic contamination of groundwater and prevalence of arsenical dermatosis in the Hetao plain area, Inner Mongolia, China. Molecular and Cellular Biochemistry 222, 137-140.

Islam, F.S., Gault, A.G., Boothman, C., Polya, D.A., Charnock, J.M., Chatterjee, D. Lloyd, J.R., 2004. Role of metal-reducing bacteria in arsenic release from Bengal delta sediments. Nature 430, 68-71.

Jarvis, A., Reuter, H.I., Nelson, A., Guevara, E., 2008. Hole-filled Seamless SRTM Data V4. International Centre for Tropical Agriculture (CIAT). Available from: http:// srtm.csi.cgiar.org.

Lee, J.J., Jang, C.S., Liu, C.W., Liang, C.P., Wang, S.W., 2009. Determining the probability of arsenic in groundwater using a parsimonious model. Environmental Science and Technology 43, 6662-6668.

Li, J., Cheng, X.T., Wang, Z.H., Wen, X.P., Han, L.L., Sang, Z.P., Zhang, J., Duan, H.S., Liang, B.F., Gao, J.G., 2007. Studies on exposure status of inhabitants to water-arsenic valence states in areas with endemic arsenism in the Datong basin in Shanxi. Frontiers of Medicine in China 1, 219-222.

Luong, T.V., Sun, G.F., Wang, L.Y., 2004. Endemic chronic arsenic poisoning - China proceedings of the 30th water, in people-centred approaches to water and environmental sanitation. 30th WEDC International Conference, Vientiane, pp. 586-589.

Mukherjee, A., Fryar, A.E., O'shea, B.M., 2009. Major occurrences of elevated arsenic in groundwater and other natural waters. In: Henke, K.R. (Ed.), Arsenic: Environmental Chemistry, Health Threats and Waste Treatment. John Wiley \& Sons, London, pp. 314-315.

Navas-Acien, A., Silbergeld, E.K., Pastor-Barriuso, R., Guallar, E., 2008. Arsenic exposure and prevalence of type 2 diabetes in US adults. Journal of the American Medical Association 300, 814-822.

Nicolli, H.B., Bundschuh, J., García, J.W., Falcón, C.M., Jean, J.S., 2010. Sources and controls for the mobility of arsenic in oxidizing groundwaters from loess-type sediments in arid/semi-arid dry climates-evidence from the Chaco-Pampean plain (Argentina). Water Research 44, 5589-5604.

Nordstrom, D.K., 2002. Worldwide occurrences of arsenic in ground water. Science 296, 2143-2145.

Pei, T., Qin, C.Z., Zhu, A.X., Yang, L., Luo, M., Li, B.L., Zhou, C.H., 2010. Mapping soil organic matter using the topographic wetness index: a comparative study based on different flow-direction algorithms and kriging methods. Ecological Indicators 10, 610-619.

Polizzotto, M.L., Kocar, B.D., Benner, S.G., Sampson, M., Fendorf, S., 2008. Nearsurface wetland sediments as a source of arsenic release to ground water in Asia. Nature 454, 505-508.

R Development Core Team, 2008. R: A Language and Environment for Statistical Computing. R Foundation for Statistical Computing, Vienna, Austria, ISBN 3-900051-07-0.

Roberts, L.C., Hug, S.J., Dittmar, J., Voegelin, A., Kretzschmar, R., Wehrli, B., Cirpka, O.A., Saha, G.C., Ashraf Ali, M., Badruzzaman, A.B.M., 2010. Arsenic release from paddy soils during monsoon flooding. Nature Geoscience 3 53-59.

Rodríguez-Lado, L., Polya, D., Winkel, L., Berg, M., Hegan, A., 2008. Modelling arsenic hazard in Cambodia: a geostatistical approach using ancillary data. Applied Geochemistry 23, 3010-3018.

Rogan, J., Chen, D.M., 2004. Remote sensing technology for mapping and monitoring land-cover and land-use change. Progress in Planning 61, 301-325.

Rowland, H.A.L., Pederick, R.L., Polya, D.A., Pancost, R.D., Van Dongen, B.E. Gault, A.G., Vaughan, D.J., Bryant, C., Anderson, B., Lloyd, J.R., 2007. The control of organic matter on microbially mediated iron reduction and arsenic release in shallow alluvial aquifers, Cambodia. Geobiology 5, 281-292.

SAGA Development Team, 2008. System for Automated Geoscientific Analyses (SAGA GIS). Germany.

Shalaby, A., Tateishi, R., 2006. Remote sensing and GIS for mapping and monitoring land cover and land-use changes in the Northwestern coastal zone of Egypt Applied Geography 27, 28-41.

Shamsudduha, M., Marzen, L.J., Uddin, A., Lee, M.K., Saunders, J.A., 2009. Spatial relationship of groundwater arsenic distribution with regional topography and water-table fluctuations in the shallow aquifers in Bangladesh. Environmental Geology 57, 1521-1535.

Smedley, P.L., 2003. Arsenic in groundwaters-south and east Asia. In: Welch, A.H., Stollenwerk, K.G. (Eds.), Arsenic in Groundwater: Geochemistry and Occurrence. Kluwer Academic Publishers, Boston, pp. 179-209.

Smedley, P.L., Kinniburgh, D.G., 2002. A review of the source, behaviour and distribution of arsenic in natural waters. Applied Geochemistry 17, 517-568.

Smedley, P.L., Zhang, M., Zhang, G., Luo, Z., 2001. Arsenic and other redox-sensitive elements in groundwater from the Huhhot Basin, Inner Mongolia. In: Cidu, R. (Ed.), Water-Rock Interaction, vol. 10. Taylor and Francis, London, pp. $181-184$. 
Sørensen, R., Zinko, U., Seibert, J., 2006. On the calculation of the topographic wetness index: evaluation of different methods based on field observations. Hydrology and Earth System Sciences 10, 101-112.

States, J.C., Srivastava, S., Chen, Y., Barchowsky, A., 2009. Arsenic and cardiovascular disease. Toxicological Sciences 107, 312-323.

Sun, G.F., 2004. Arsenic contamination and Arsenicosis in China. Toxicology and Applied Pharmacology 198, 268-271.

Tondel, M., Rahman, M., Magnuson, A., Chowdhury, I.A., Faruquee, M.H. Ahmad, S.A., 1999. The relationship of arsenic levels in drinking water and the prevalence rate of skin lesions in Bangladesh. Environmental Health Perspectives 107, 727-729.

Tseng, C.H., Tai, T.Y., Chong, C.K., Tseng, C.P., Lai, M.S., Lin, B.J., Chiou, H.Y., Hsueh, Y.M. Hsu, K.H., Chen, C.J., 2000. Long-term arsenic exposure and incidence of noninsulin-dependent diabetes mellitus: a cohort study in arseniasis-hyperendemic villages in Taiwan. Environmental Health Perspectives 108, 847-851.

Tseng, W.P., 1977. Effects and dose-response relationships of skin cancer and blackfoot disease with arsenic. Environmental Health Perspectives 19, 109-119.

Twarakavi, N.K.C., Kaluarachchi, J.J., 2006. Arsenic in the shallow ground waters of conterminous United States: assessment, health risks, and costs for $\mathrm{MCL}$ compliance. Journal of the American Water Resources Association 42, 275-294.

Wang, L.F., Huang, J.Z., 1994. Chronic arsenism from drinking water in some areas of Xinjiang, China. In: Nriagu, J.O. (Ed.), Arsenic in the Environment, Part II: Human Health and Ecosystem Effects. John Wiley and Sons Inc., New York, pp. 159-172.

Wang, S.X., Li, J., Wang, Z.H., 2008. Report of screening of water arsenic and investigation of endemic arsenism in Shanxi. Chinese Journal of Endemiology 27, 61-64 (in Chinese)

Wang, S.X., Wang, Z.H., Cheng, X.T., Li, J., Sang, Z.P., Zhang, X.D., Han, L.L., Qiao, X.Y., Wu, Z.M., Wang, Z.Q., 2007. Arsenic and fluoride exposure in drinking water: children's IQ and growth in Shanyin County, Shanxi Province, China. Environmental Health Perspectives 115, 643-647.

Wang, Y.X., Shvartsev, S.L., Su, C.L., 2009. Genesis of arsenic/fluoride-enriched soda water: a case study at Datong, northern China. Applied Geochemistry 24, 641-649.

Wang, Z.H., Li, J., Cheng, X.T., 2004. The epidemiological state of endemic arsenism in Shanxi province. Chinese Journal of Endemiology 23, 362-364 (in Chinese). WHO, 2001. Arsenic and Arsenic COMPOUNDS, Environmental Health Criteria 224. World Health Organization, Geneve.

Winkel, L., Berg, M., Amini, M., Hug, S.J., Johnson, C.A., 2008. Predicting groundwater arsenic contamination in Southeast Asia from surface parameters. Nature Geoscience 1, 536-542.

Winkel, L, Trang P.T.K, Lan, V.M., Stengel, C., Amini, M., Ha, N.T. Viet, P.H., Berg, M. 2011. Arsenic pollution of groundwater in Vietnam exacerbated by deep aquifer exploitation for more than a century. Proceedings of the National Academy of Sciences of the United States of America 108, 1246-1251.

Xie, X.J., Ellis, A., Wang, Y.X., Xie, Z.M., Duan, M.Y., Su, C.L., 2009. Geochemistry of redox-sensitive elements and sulfur isotopes in the high arsenic groundwater system of Datong Basin, China. Science of the Total Environment 407, 3823-3835.

Xie, X.J., Wang, Y.X., Su, C.L., Liu, H.Q., Duan, M.Y., Xie, Z.M., 2008. Arsenic mobilization in shallow aquifers of Datong Basin: hydrochemical and mineralogical evidences. Journal of Geochemical Exploration 98, 107-115.

Yimer, F., Ledin, S., Abdelkadir, A., 2006. Soil property variations in relation to topographic aspect and vegetation community in the south-eastern highlands of Ethiopia. Forest Ecology and Management 232, 90-99.

Yu, G.Q., Sun, D.J., Zheng, Y., 2007. Health effects of exposure to natural arsenic in groundwater and coal in China: an overview of occurrence. Environmental Health Perspectives 115, 636-642. 